\title{
Improved Thiocyanate-Selective Electrode Based on Tetra(trimethylphenyl)- porphyrinato Manganese(III) Chloride: The Electronic and pH Effects
}

\author{
Hyung Ran Seo, Hyo Kyoung Lee, and Seungwon Jeon* \\ Department of Chemistry and Institute of Basic Science, Chonnam National University. Gwangu 500-757, Korea \\ Received Mav 28, 2004
}

\begin{abstract}
The thiocyanate-selective PVC membrane electrodes based on 5.10.15,20-tetrakis(2.4.6-trimethylphenyl)porphỵrinatomanganese(III) chloride $[\mathrm{Mn}(\mathrm{TMP}) \mathrm{Cl}]$ and 5,10,15.20-tetrakis(2,6-dichlorophenyl)porphy rinatomanganese(III) chloride $\left[\mathrm{Mn}\left(\mathrm{Cl}_{8} \mathrm{TPP}\right) \mathrm{Cl}\right]$ as ion carriers were imvestigated. The effect of ionophores. membrane compositions. plasticizers. and solution $\mathrm{pHs}$ on the response characteristics were studied. The $\mathrm{Mn}(\mathrm{TMP}) \mathrm{Cl}$ as an ionophore shows the best potentiometric sensitivity with a slope of $-58.7 \mathrm{mV} /$ decade and a detection limit of $\log \left[\mathrm{SCN}^{-}\right]=-6.90$. and selectivity for thiocyanate over strong hydrophobic interfering anions such as $\mathrm{ClO}_{4}^{-}$and salicy late. The potentiometric response is affected by the electronic effect of the substituents and solution $\mathrm{pHs}$. The presence of substituents with electron donating and more liphophilic characters around the ligated metal center produces an improved response toward $\mathrm{SCN}^{-}$.
\end{abstract}

Key Words : Ion-selective electrodes. Manganese porplyyins, Potentiometric deternination, Poly meric membrane. Thiocyanate ion

\section{Introduction}

Ion-selective electrodes (ISEs) as potentiometric sensors are considered as useful analytical devices, and provide some benefits such as portable, rapid. inexpensive. and simple method for the determination of ionic species. The selective detection of many anions has a critical drawback such as the classical Hofmeister series that is correlated with a preference for hydrophobic anions. Therefore, the need for ionophores with improved selectivities and sensitivities in the field of anion-selective electrodes is increased. A very interesting development in the field of ion-selective electrodes (ISEs) is the preparation of electrodes that can chenucally recognize specific anions and offer potentiometric responses that differ from the conventional anion-exchangerbased membranes. One of new carriers with anti-Hofmeister that can be used in the development of potentiometrically chemical sensors should be metalligand interactions. Metalloporphyrins, ${ }^{1-5}$ metallophthalocyanines, ${ }^{6}$ cyclometallic anines, ${ }^{7}$ Schiff base complexes. ${ }^{8-13}$ and $\mathrm{N}_{\mathrm{A}}$-metal complexes ${ }^{14-17}$ have been observed to show such specific metalligand interactions. ISEs based on these metalligand interactions have been reported for the determination of thiocyanate anion. and they showed the deviation from the classical Hofmeister series. Among then. metalloporphyrins have been interested owing to their ion-discriminating ability, the diversity of their structures, and the selective axial ligation between the central metal and primary anion. ${ }^{18-2(9)}$ It was well known that the substitution at meso- or pyrrole-positions of porphyrins was found to cause a change of redox potential and solubility in solvent media. ${ }^{21.22}$ It was reported that the potentiometric response of thiocyanate-selective electrodes was affected by the structure of manganese porphyrins and the lipophilic sites of additive ${ }^{3.2 .24}$ In the present study, we want to report the improved potentiometric properties towards thiocyanate anion for the polymeric electrode based on manganese(III) tetra(trimethylphenyl)porphyrin chloride [Mn(TMP)Cl] due to the electronic effect of substituent at meso-position of porplyrin ring. PVC polymeric membranes based on $\mathrm{Mn}(\mathrm{TMP}) \mathrm{Cl}$ and $\mathrm{Mn}\left(\mathrm{Cl}_{8} \mathrm{TPP}\right) \mathrm{Cl}$ were characterized for the selective determination of thiocyanate anion.

\section{Experimental Section}

Reagents. $\mathrm{Mn}(\mathrm{TMP}) \mathrm{Cl}$ (I) and $\mathrm{Mn}\left(\mathrm{Cl}_{8} \mathrm{TPP}\right) \mathrm{Cl}$ (II) tested as thiocyanate ionophores are shown in Figure 1. They were synthesized and purified according to the literatures ${ }^{25.36} \mathrm{in}$ our laboratory. High molecular weight PVC, dioctyl sebacate (DOS). dioctyl plithalate (DOP), dioctyl adipate (DOA). 2nitrophenyl octyl ether ( $o$-NPOE). tridodecylmethylanumonium chloride (TDDMACl). and tetralydrofuran (THF), which were obtained from Fluka, were used to prepare PVC membrane electrodes. Analytical grade sodium and potassium salts of tested anions were used. All other chemicals used were analytical grade. Doubly distilled water in a quartz apparatus was used to prepare all aqueous electrolyte solutions. The solutions were adjusted to the given $\mathrm{pH}$ using $0.05 \mathrm{M} \mathrm{H}_{3} \mathrm{PO}_{4}-\mathrm{NaOH}$ buffer.

Preparation of polymeric thiocyanate-selective electrodes. Membrane solutions were prepared by dissolving varying amounts of the manganese porphyrins, together with appropriate amounts of plasticizers, and PVC in about $1 \mathrm{~mL}$ of THF and mechanically stirred. TDDMACl as membrane additive was also incorporated in some of the membranes. Several blank membranes were also prepared by incorporating the additive into plasticized PVC in the absence of the porphyrins. The typical compositions of PVC-based thiocyanate-selective electrodes were summarized in Table 1 All membrane cocktails were cast in glass rings placed on glass plates for conventional ion-selective electrodes. 


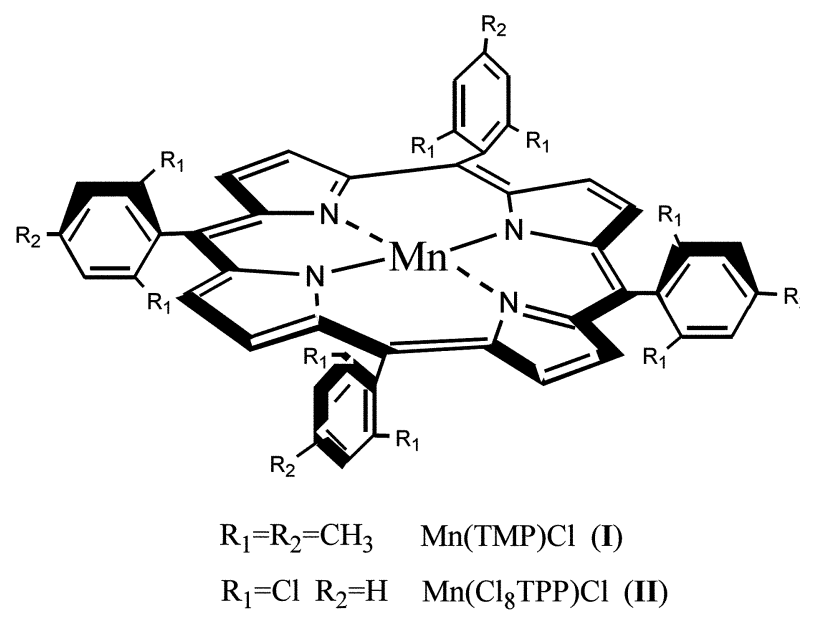

Figure 1. Macromolccular structures of substituted manganese( III) porphytins (I and ll) used in this study.

Solvent from PVC membrane was allowed to evaporate for a day at room temperature. The thickness of the polymeric membrane was about $0.3 \mathrm{~mm}$.

Potentiometric measurements. Small disks were punched from the cast membranes and mounted in Philips electrode bodies (IS-561). For all electrodes, $0.1 \mathrm{M} \mathrm{KCl}$ was used as an internal filling solution. The external reference electrode was an Orion sleeve-type double-junction $\mathrm{Ag} / \mathrm{AgCl}$ reference electrode (Model 90-02). The potentiometric responses of the thiocyanate-selective electrodes were measured in the conventional configuration. The electrodes were equilibrated for $24 \mathrm{~h}$ in $0.01 \mathrm{M}$ potassium thiocyanate solution. The potential measurements were carried out at $25 \pm 1^{\circ} \mathrm{C}$ with Kosentech 16-channel potentiometer (KST101-1) coupled to a computer by setting up the following cell assembly:

$\mathrm{Ag} / \mathrm{AgCl}, \mathrm{KCl}$ (sat'd) | sample solution PVC membrane.

The dynamic response curves were produced by adding standard solutions of anions to magnetically stirred buffer solution. The $\mathrm{pH}$ of sample solutions was monitored simultaneously with a conventional glass $\mathrm{pH}$ electrode. Calibration curves were constructed by plotting the potential (EMF) versus logarithm of the concentration of thiocyanate at constant $\mathrm{pH}$.

The selectivity coefficients ( $\log K_{S C N}^{p o t}$ ) were determined by separate solution method (SSM) using salts of the anions involved. The slope was obtained by plotting the calibration curve in the concentration range of $10^{-6}$ to $10^{-1} \mathrm{M}$. Activity coefficients were assumed to be constant for all of the primary ions, and no correction was made for slight changes in the liquid junction potential of the reference electrode. At least three-time measurements were performed, and the data were determined from the plot. Before each set of measurements, the electrodes were soaked in doubly distilled water.

\section{Results and Discussion}

The potentiometric rosponse. Among metalloporphyrins. the derivatives of manganese porphyrin as an ionophores exhibit high thiocyanate sensitivity and selectivity in the polymeric membranes. Manganese porphyrins having strong electron donating groups at meso-positions of porphyrin shift to cathodic direction in redox potentials. An effect of PVC membrane composition on the potentiometric response and selectivity of the ionophore-based membranes were extensively studied. The composition of these membranes is presented in Table 1. Typical results for the thiocyanate selective electrodes $\mathrm{m}^{-1}$ and $\mathrm{m}-8$ based on $\mathrm{Mn}(\mathrm{TMP}) \mathrm{Cl}$ and $\mathrm{Mn}\left(\mathrm{Cl}_{8} \mathrm{TPP}\right) \mathrm{Cl}$ as ionophores, respectively, are shown in Figure 2. The potentiometric results for $\mathrm{SCN}^{-}$anion were summarized in Tables 1 and 2. The polymeric membrane based on $\mathrm{Mn}(\mathrm{TMP}) \mathrm{Cl}$ exhibits a linear stable response over a concentration range $\left(1.5 \times 10^{-7}-1.0 \times 10^{-1} \mathrm{M}\right)$ with a slope of $58.7 \mathrm{mV} /$ decade and a detection limit of $\log \left[\mathrm{SCN}^{-}\right]=$ -6.90 , and this Nernstian is for a monovalent anion response. When compared with $\mathrm{Mn}(\mathrm{TMP}) \mathrm{Cl}$ having an electron donating groups, the membrane based on $\mathrm{Mn}\left(\mathrm{Cl}_{8} \mathrm{TPP}\right) \mathrm{Cl}$ that has an electron withdrawing groups shows a slightly higher detection limit of $\log \left[\mathrm{SCN}^{-}\right]=-6.61$. This result agrees with the previous literature that reported a detection

Table 1. The membrane compositions for thiocyanate-selective clectrodes

\begin{tabular}{|c|c|c|c|c|c|c|c|}
\hline $\begin{array}{l}\text { Mem- } \\
\text { brane }\end{array}$ & $\begin{array}{c}\text { lonophore } \\
\text { (mg) }\end{array}$ & P'VC' & $\mathrm{DOP}^{x}$ & $\mathrm{DOS}^{27}$ & o-.NPOE" & $D O A^{\prime \prime}$ & $\begin{array}{l}\mathrm{IIDT})- \\
\mathrm{M} \wedge \mathrm{Cl}\end{array}$ \\
\hline $\mathrm{m}-1$ & l(1) & 33 & 66 & & & & \\
\hline $\mathrm{m}-2$ & l(3) & 33 & 66 & & & & \\
\hline $\mathrm{m}-3$ & $\mathrm{l}(5)$ & 33 & 66 & & & & \\
\hline$m-4$ & l(1) & 33 & & 66 & & & \\
\hline$m-5$ & l(1) & 33 & & & 66 & & \\
\hline$m-6$ & l(1) & 33 & & & & 66 & \\
\hline$m-7$ & l(1) & 33 & 66 & & & & 50 \\
\hline $\mathrm{m}-8$ & ll( 1 ) & 33 & 66 & & & & \\
\hline $\mathrm{m}-9$ & ll( 1 ) & 33 & & 66 & & & \\
\hline$m-10$ & $11(1)$ & 33 & & & 66 & & \\
\hline$m-11$ & ll(1) & 33 & & & & 66 & \\
\hline
\end{tabular}

"In mg. "mol\% relative to the ionophore.

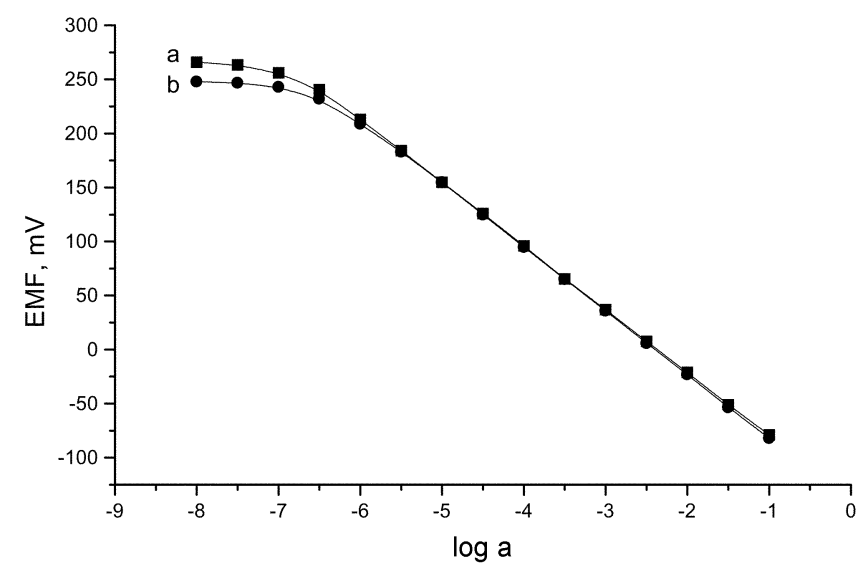

Figure 2. The potentiometric responses of the membranes (a) m-1 of ionophore I and (b) m-8 of jonophore II towards thiocyanate anion in $\mathrm{pH} 3.0$ buffer solutions. 


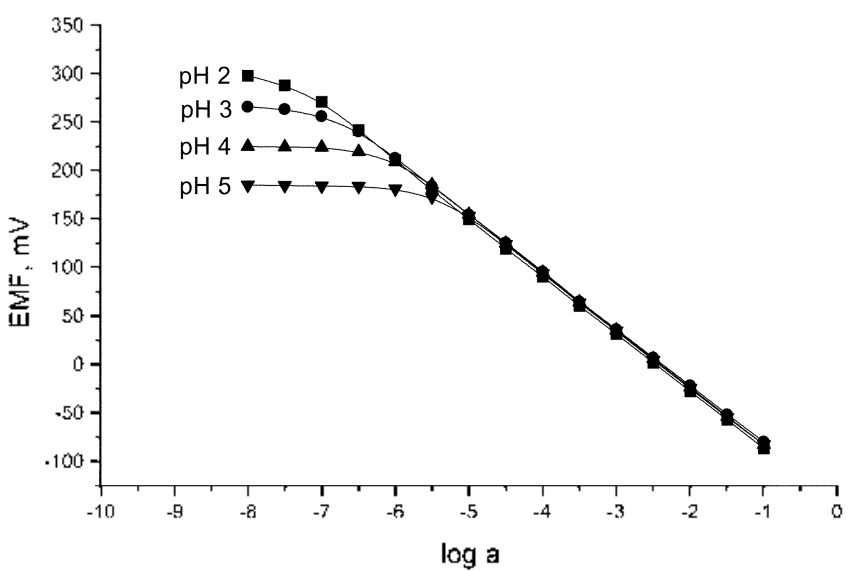

Figure 3. The thiocyanate responses of the membrane m-1 of ionophore I in different pl I buffer solutions.

limit of $\log \left[\mathrm{SCN}^{-}\right]=-6.49$ for the membrane based on (octabromotetraphenylporphyrinato) manganese(III) chloride indicating an electron withdrawing effect [4].

Because the polymeric membranes based on transition metal complexes as ionophores can show significant $\mathrm{pH}$ sensitivity, the potentiometric responses of the membranes were measured at different $\mathrm{pH}$ solutions with the concentrations of target thiocyanate anion. Figure 3 shows the $\mathrm{pH}$ dependence of potentiometric responses of PVC membrane electrode (m-1) prepared from Mn(TMP)CI with DOP as a plasticizer. As it can be seen in Figure 3, the response of the membrane is hardly affected by $\mathrm{pH}$ changes in the high concentrations above $10^{-5} \mathrm{M}$ thiocyanate, but depends on the solution $\mathrm{pHs}$ in the low concentrations below $10^{-6} \mathrm{M}$ thiocyanate. In order to convince these results, the separate experiments were carried out. When $\mathrm{pH}$ dependence of potentiometric response for the membrane (m-1) was measured in $10^{-3} \mathrm{M}$ thiocyanate solution between $\mathrm{pH} 2$ and 10 , the membrane potentials were constant with the solution $\mathrm{pHs}$ employed. Similar results were obtained from the membranes based on other compositions. However, the membrane potentials were decreased with the increase of the solution $\mathrm{pHs}$ in $10^{-7} \mathrm{M}$ thiocyanate solution. These results indicate that the metal center of manganese porphyrins is crucial for the $\mathrm{pH}$ dependence of the membranes. $\mathrm{OH}^{-}$and $\mathrm{SCN}^{-}$ions can coordinate competitively to the axial position of the metal center. The potentiometric response in the region of low concentrations of $\mathrm{SCN}^{-}$ion is reduced due to the interference of $\mathrm{OH}^{-}$at high $\mathrm{pHs}$ which exist higher concentration of $\mathrm{OH}^{-}$, but it in the region of high concentrations of $\mathrm{SCN}^{-}$ion is hardly affected by $\mathrm{OH}^{-}$. Therefore, a pH of 3 was chosen for further experiments in order to minimize the effect of $\mathrm{OH}^{-}$and to consider solution acidity.

The capacity of jonophore contained in the membranes is optimized by preparing membranes with $66 \mathrm{mg} \mathrm{DOP}, 33 \mathrm{mg}$ PVC, and differing capacities of the ionophore I, ranging from 0.0 to $5.0 \mathrm{mg}$. Several thiocyanate calibrations are performed using each membrane. The thiocyanate responses as a function of the capacity of ionophore in $0.05 \mathrm{M} \mathrm{H}_{3} \mathrm{PO}_{4}-$

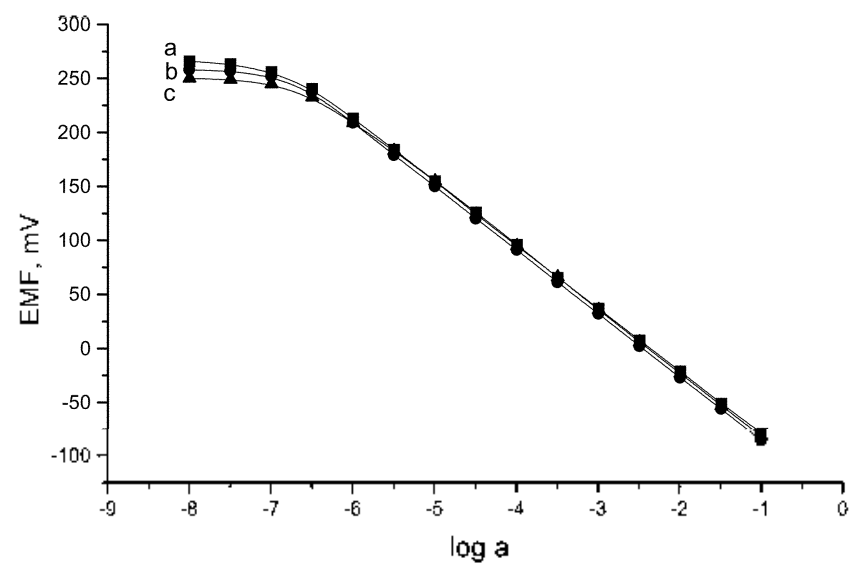

Figure 4. The thiocvanate responses as a function of the capacity of ionophore $\mathrm{l}$ in $\mathrm{pH} 3.0$ buffer solutions. (a) $1 \mathrm{mg}$. (b) $3 \mathrm{mg}$. (c) $5 \mathrm{mg}$.

$\mathrm{NaOH}$ of $\mathrm{pH} 3.0$ buffer solutions are shown in Figure 4. Based on the detection limit and the slope, the optimal capacity of ionophore $\mathrm{Mn}(\mathrm{TMP}) \mathrm{Cl}$ is $1 \mathrm{mg}$ in the PVC membrane. Above $1 \mathrm{mg}$ the responses of the ISE: in terms of detection limit of the calibration curve fall off a little. This result is different with one obtained from coated-graphite electrodes using manganese porphyrins, ${ }^{2}$ and indicates that the polymeric membranes are more effective than coated electrodes in small quantity of ionophore. Therefore, membranes with $1 \%$ ionophore were used for all experiments.

The effect of plasticizers used was investigated in PVC polymeric membranes containing $1 \mathrm{mg}$ ionophore $\mathrm{Mn}(\mathrm{TMP}) \mathrm{Cl}, 33 \mathrm{mg}$ PVC, and $66 \mathrm{mg}$ plasticizers. Figure 5 illustrates the thiocyanate calibration curves for their

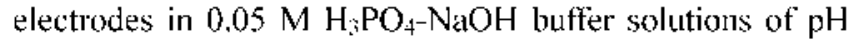
3.0. Membranes fabricated by DOP showed the best detection limit, the best linear range, and most Nernstian slopes for $\mathrm{SCN}^{-}$anion. $\mathrm{DOP}$ was chosen as a proper plasticizer in the $\mathrm{SCN}^{-}$-ISE membranes.

The effect of the lipophilic cationic additive (TDDMACl) on the response characteristics of the membranes was investigated by incorporation of 50 and $100 \mathrm{~mol} \%$ of this

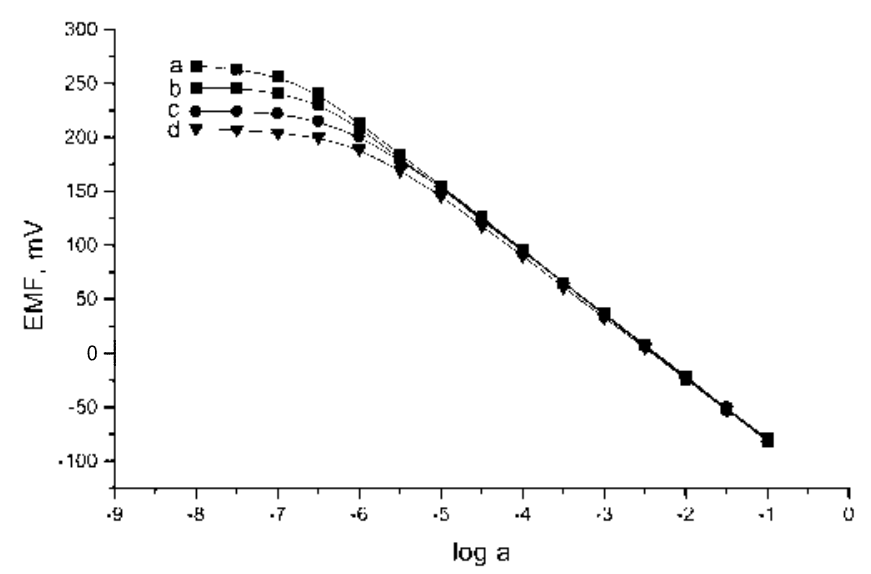

Figure 5. The thiocyanate responses of the membranes prepared from different plasticizer with ionophore I in pH 3 buffer solutions. (a) DOP. (b) DOS. (c) DOA. (d) $0-N P O E$. 
compound into the membranes. When the additive was contained in the membrane, the slope of the calibration plots was Nernstian value, but the linear ranges were decreased. This additive significantly affected the selectivity of the electrodes as will be discussed in the next section.

An optimum equilibration time was investigated by conditioning membrane electrodes in $10^{-2} \mathrm{M}$ thiocyanate solutions for periods of 12,24 , and $48 \mathrm{~h}$. The optimum time was found to be $24 \mathrm{~h}$ for obtaining stable potentials in contact with thiocyanate solution. A response time was tested by measuring the time required to get a steady state potential $( \pm 1 \mathrm{mV})$ after successive additions of thiocyanate ion. The static response times of different electrodes were below 5 seconds, and these novel prepared electrodes do not display any hysteretic effects. The reproducibility and stability of the electrodes were tested by repeated calibrations over periods of 3 months. Repeated monitoring of potentials and calibration, using the same electrode of $\mathrm{m}-1$. gave good slope reproducibility. After 3 months, the electrode was responding at $97 \%$ of the initial response. The prolong lifetime of the membrane as the thiocyanate ISF: is due to the relatively higher lipophilicity of $\mathrm{Mn}(\mathrm{TMP}) \mathrm{Cl}$.

Selectivity of the electrodes. The most important characteristic of any ion-sensitive electrode is its relative response for the primary ion over interfering ions present in solution, which is expressed in terms of potentiometric selectivity coefficients. It is interesting to compare the potentiometric selectivity of the membranes containing different ionophores, plasticizers, and additive. Typical results of the logarithmic selectivity coefficients, $\log \mathrm{K}_{\mathrm{SCN}}{ }^{-},{ }_{j}$, obtained from the electrode responses of various membranes are given in Table 2. The thiocyanate responses of the membrane to ten interfering anions were tested under the determined optimal conditions. Using an electrode based on a quatemary ammonium salt (TDDMACl), the potentiometric response follows the Hofmeister series, $\mathrm{ClO}_{4}^{-}>$ $\mathrm{SCN}^{-}>$salicylate $>\mathrm{I}^{-}>\mathrm{NO}_{3}^{-}>\mathrm{Br}^{-} \sim \mathrm{N}_{3}^{-}>\mathrm{NO}_{3}^{-}>\mathrm{NO}_{2}{ }^{-}>$ $\mathrm{Cl}^{-}>\mathrm{CH}_{3} \mathrm{COO}^{-}>\mathrm{SO}_{4}{ }^{2-}$. Among the nembranes tested, the membrane (m-1) of ionophore I gives the good selectivity. The selectivity series of the membrane containing ionophore 1 gives the follow as $\mathrm{SCN}^{-}>$salicylate $>1^{-}>\mathrm{ClO}_{4}^{-}>\mathrm{NO}_{2}^{-}$ $\mathrm{CH}_{3} \mathrm{COO}^{-} \ldots \mathrm{HCO}_{3}^{-} \ldots \mathrm{N}_{3}^{-}>\mathrm{NO}_{3}^{-} \ldots \mathrm{Br}^{-} \ldots \mathrm{Cl}^{-}$, and this series is totally different with Hofmeister series. This ionophore-based ISE: exhibited excellent selectivity for $\mathrm{SCN}^{-}$anion over every anion tested. The inembranes containing TDDMACl as an additive, clearly show more tendency for the highly lipophilic anions such as $\mathrm{ClO}_{4}{ }^{-}$and salicylate. In fact, the electrode containing TDDMACl ionophore is more selective to $\mathrm{ClO}_{4}{ }^{-}$than thiocyanate. Such behavior was observed for all ionophores studied in this work. This is consistent with the reports on the use of quaternary ammonium salts for the development of perchlorate-selective electrodes. Since the response of the classical ion-exchangers is based on the lipophilicity of anions, these electrodes are essentially nonselective.

The response of manganese porphyrins toward the primary anion is related to the ligation to the metal center, and manganese porphyrins act as an ionophore of $\mathrm{SCN}^{-}$in the membranes. Above results suggest that the ligation ability of $\mathrm{SCN}^{-}$to the metal center is larger than any interfering anions. The sensitivity and selectivity towards $\mathrm{SCN}^{-}$for the membranes are affected by the electronic effect of ionophores, and ionophore I having electron donating groups provides the stronger response to $\mathrm{SCN}^{-}$rather than ionophore II and (octabromotetraphenylporphyrinato)manganese(III) chloride having electron withdrawing groups [4]. Figure 6 also shows a trace for the response to $100 \mathrm{~mL}$.

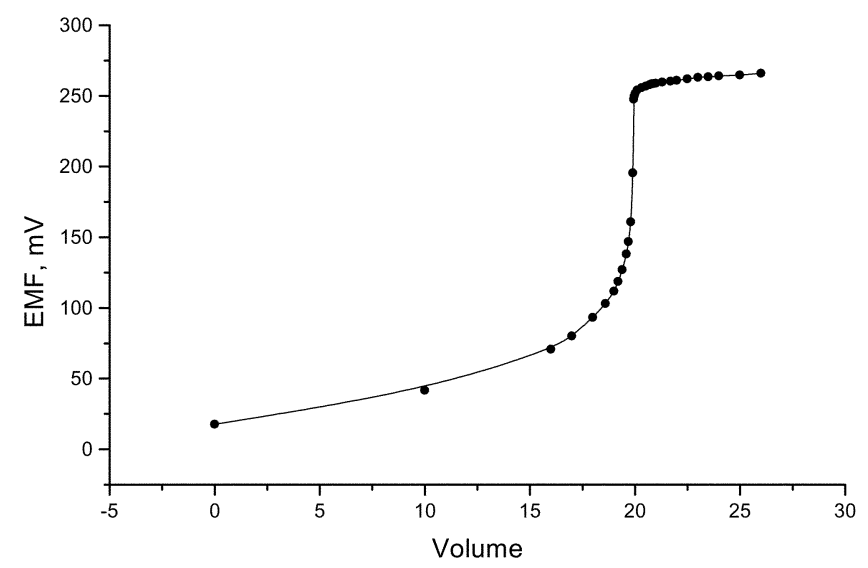

Figure 6. The potentiometric titration curve for $100 \mathrm{~mL}$ of $1.0 \times 10^{-3} \mathrm{M}$ NaSC.V with $5.0 \times 10^{-3} \mathrm{M}$ silver nitrate in $\mathrm{pH} 3$ butficr solution.

Table 2. Electrochemical properties of PVC-based thiocyanate-selective electrodes

\begin{tabular}{|c|c|c|c|c|c|c|c|c|c|c|c|c|}
\hline \multirow{2}{*}{ Membrane } & \multirow{2}{*}{$\begin{array}{c}\text { Slope } \\
(m V / d e c .)\end{array}$} & \multirow{2}{*}{$\begin{array}{c}\text { Detection limit } \\
\left(\log \left|S C N^{-1}\right|\right)\end{array}$} & \multicolumn{10}{|c|}{ 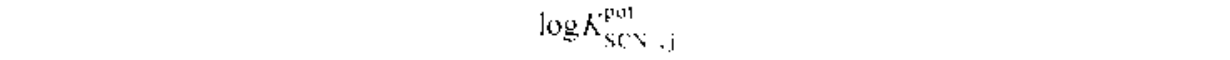 } \\
\hline & & & $\mathrm{ClO}_{4}^{-}$ & $\mathrm{Sal}^{-}$ & $\mathrm{I}^{-}$ & $\mathrm{NO}_{\mathrm{s}}^{-}$ & $\mathrm{NO}_{2}^{-}$ & $\mathrm{Cl}^{-}$ & $13 \mathrm{r}^{-}$ & $\mathrm{N}_{3}^{-}$ & $\mathrm{ICO}_{3}^{-}$ & $\mathrm{CH}_{3} \mathrm{COO}^{-}$ \\
\hline$m-1$ & -58.7 & -6.90 & -3.3 & $-2,0$ & -2.4 & -4.5 & -3.7 & -4.7 & -4.5 & -3.8 & -3.8 & -3.7 \\
\hline$m-2$ & -58.9 & -6.84 & -2.0 & -1.6 & -1.4 & -3.4 & -3.5 & -3.4 & -2.7 & -3.5 & -3.8 & -3.5 \\
\hline$m-3$ & -58.0 & -6.70 & -2.6 & $-1,8$ & -1.5 & -4.0 & -3.3 & -3.3 & -2.6 & -3.5 & -3.7 & -3.7 \\
\hline$m-4$ & $-57,9$ & -6.25 & -2.7 & -1.7 & -1.5 & -3.3 & -3.1 & -3.2 & $-2,5$ & -3.3 & -3.7 & -3.7 \\
\hline$m-6$ & -58.5 & -6.60 & -2.4 & -1.7 & -1.6 & -3.2 & -3.1 & -3.1 & -2.8 & -3.5 & -3.8 & -3.7 \\
\hline$m-7$ & -580 & -6.23 & 0.3 & -0.3 & -1.5 & -2.2 & -2.3 & -2.2 & -2.7 & -3.3 & -3.8 & -3.6 \\
\hline$m-8$ & -58.7 & -6.61 & -3.2 & -1.5 & -1.7 & -4.3 & -3.6 & -3.6 & -2.7 & -3.7 & -3.8 & -3.7 \\
\hline$m-9$ & -55.7 & -5.30 & -3.0 & $-1,4$ & -1.1 & -3.1 & -3.2 & -3.0 & -2.1 & -3.5 & -3.7 & -3.8 \\
\hline$m-1]$ & -54.3 & -5.29 & -3.2 & -1.5 & $-1,0$ & -3.4 & -3.2 & -3.0 & -2.3 & -3.4 & -3.8 & -3.8 \\
\hline
\end{tabular}


solution of the $1.0 \times 10^{-3} \mathrm{M} \mathrm{NaSCN}$ by the titration with $5.0 \times 10^{-3} \mathrm{M} \mathrm{AgNO}_{3}$ solution. The response through the titration indicates that the amount of $\mathrm{SCN}^{-}$ion in solution can be accurately determined from the resulting neat titration curve providing a good end point.

\section{Conclusions}

The widest linear dynanic range and lowest linit of detection were observed for their electrodes in the absence of any additive. but the addition of additive to the membrane made the deterioration. The substituents on the porphyrin structure were found to cause a significant effect on the sensitivities and selectivities for thiocyanate over several intefering anions. The best results were obtained from the membrane electrodes incorporating $\mathrm{Mn}(\mathrm{TMP}) \mathrm{Cl}$ as a ionophore in the absence of additive. These results inply that the potentionetric response is affected by the electronic effect of the porphyrin substituents and solution $\mathrm{pH}$. It is concluded that the presence of substituents with electron donating and more liphophilic characters around the ligated metal center produces an improved response toward $\mathrm{SCN}^{-}$ over perchlorate and salicy late.

Acknowledgments. This work was supported by Cholutam National University (2004).

\section{References}

1. Gao. D.: Gu. J.: Yu. R.-Q.: Zheng. G.-D. Anal. Chim. Acta 1995. 302.263

2. Khorasani. J. H.: Amini. M. K.: Motaghi. H.: Tangestaninejad. S.: Moghadam, M. Sensors and Actwators B Chem. 2002, 87, 4.48.

3. Daumert S; Wallace, S.; Florido, A.; Bachas, L. Anat Chent. 1991, 63, 1676

4. Shamsipur. M.: Khayatian. G.: Tangestaninejad. S. Electroumalysis 1999. 11. 1340

5. Li. Z.-Z.: Zhang. X.-B.: Guo. C.-C.: Shen. G.-L.: Yu. R.-Q. Aral. Sci. 2002, 18. 423.
6. Amini. M. K.: Shahrokhian1. S: Tangestaninejad. S. Anal. Chim. Acta 1999. 402.137

7. Sanchez-Pedreno, C.: Ortuno, J. A.; Martinez. D. Talama 1998. 47. 305 .

8. Amini. M. K.: Rafi, A.; Ghaedi. M.: Habibi, M. H: Zohory: M. M Hicrochemical J. 2003. 75. 143.

9. Yuan. R.: Wang. X. L.: Xu. L.: Chai. Y. Q.: Sun1. Z. Y.: Huang. X. Q.: Li. Q. F.: Zhao. Q.: Zhou. L. Electrochem. Comm 2003. 5. 717.

10. Li. Z.-Q.: Wu, Z.-Y: Yuan. R.: Yng. M.: Shen, G.-L:; Yu. R.-Q. Electrochinca Acta 1999. 44, 2543.

11. Sur1. Z.-Y:: Yuan1. R.: Chai. Y.-Q: Xu. L:: Gan. X.-X:: Xu. W.-J. And Bioanal. Chem. 2004. 378. 490.

12. Ganjali. M. R.: Poursaberi. T.: Basiripour. F.: Salavati-Niassari. M.: Yousefi. M.: Shamsipur. M. Fresenins J. Anal Chem. 2001. 370. 1091

13. Ying. M.; Yuan. R.: Li, Z,-Q: Song. Y.-Q.: Li, W.-X.: Lin. H.-G.: Shet1. G.-L.: Yu. R.-Q. Fresemits I. Anal Chem 1998. 361. 437.

14. Abbaspour. A.: Kamyabi. M. A.: Esmaeilbeig. A. R.: Kia. R. Talama 2002. 57.859 .

15. Ardakani. M. M. Ensafi. A. A.; Niasari, M. S.: Chahooki. S. M. Anal. Chm . Acta 2002, 462, 25 .

16. Ganjali. M. R.: Yousefi. M.: Jałanbakht. M.: Poursaberi. T.: Salavati-Niassari. M: Hajiagha-Babaei. L:: Latifi. E.: Shamsipur. M. Anal. Sci. 2002 . 18. 887.

17. Poursaber, T.; Salavati-Niassari, M.: Khodabakhsh, S.; HajiaghaBabaei. L.: Shamsipur. M.: Yousefi. M.: Rouhani. S.: Ganjali, M. R. Anal. Lett. 2001. 3+, 2621

18. Gupta. V. K. Jain. A. K.: Singh. L. P. Anal. Chim. Acta 1999. 379 201

19. Zhan1. X. B.: Guo. C. C.: Xu. T. B.: Shet1. G. L.: Yu. R. Q. Andlyst 2000. 125,867

20. Brown, D. B.: Chaniotakis, N. A.: Lee, I. H.; Ma. S. C.; Park, S B.: Meverhoff, M. E. Electroamahsis $1989,1,477$.

21. Giradeau. A.: Callot. H. J.: Tordant. T.: Ezhar. I.: Gross. M. J. Am Chem. Soc. 1979. 101. 3857

22. Jeot1. S.: Bruice. T. C. horg. Chem. 1992. 31.4843.

23. Chaniotakis, N. A.: Chasser. A. M.: Meverhoff. M. E.; Groves, J T. Anal Chem $1988,60,185$.

24. Bakker. E; Malinowska, E.: Schiller, R. D.: Meverhoff, M. E. Talanta 1994. H. 881.

25. Lindsey. J. S.: Wagner. R. W. J. Org. Chem. 1989. 54. 828.

26. Arasasingham. R. D.: Bruice. T. C. J. Am. Chem Soc. 1991. 113. 6095 . 